\title{
A novel PCR-based method for high throughput prokaryotic expression of antimicrobial peptide genes
}

\author{
Tao Ke ${ }^{1,2^{*}+}$, Su Liang ${ }^{3 \dagger}$, Jin Huang ${ }^{3}$, Han Mao², Jibao Chen', Caihua Dong ${ }^{2}$, Junyan Huang ${ }^{2}$, Shengyi Liu², \\ Jianxiong Kang ${ }^{4}$, Dongqi Liu ${ }^{4}$ and Xiangdong $\mathrm{Ma}^{3^{*}}$
}

\begin{abstract}
Background: To facilitate the screening of large quantities of new antimicrobial peptides (AMPs), we describe a cost-effective method for high throughput prokaryotic expression of AMPs. EDDIE, an autoproteolytic mutant of the N-terminal autoprotease, Npro, from classical swine fever virus, was selected as a fusion protein partner. The expression system was used for high-level expression of six antimicrobial peptides with different sizes: Bombininlike peptide 7, Temporin G, hexapeptide, Combi-1, human Histatin 9, and human Histatin 6. These expressed AMPs were purified and evaluated for antimicrobial activity.

Results: Two or four primers were used to synthesize each AMP gene in a single step PCR. Each synthetic gene was then cloned into the pET30a/His-EDDIE-GFP vector via an in vivo recombination strategy. Each AMP was then expressed as an Npro fusion protein in Escherichia coli. The expressed fusion proteins existed as inclusion bodies in the cytoplasm and the expression levels of the six AMPs reached up to $40 \%$ of the total cell protein content. On in vitro refolding, the fusion AMPs was released from the C-terminal end of the autoprotease by self-cleavage, leaving AMPs with an authentic $\mathrm{N}$ terminus. The released fusion partner was easily purified by Ni-NTA chromatography. All recombinant AMPs displayed expected antimicrobial activity against E. coli, Micrococcus luteus and S. cerevisia.

Conclusions: The method described in this report allows the fast synthesis of genes that are optimized for overexpression in E. coli and for the production of sufficiently large amounts of peptides for functional and structural characterization. The Npro partner system, without the need for chemical or enzymatic removal of the fusion tag, is a low-cost, efficient way of producing AMPs for characterization. The cloning method, combined with bioinformatic analyses from genome and EST sequence data, will also be useful for screening new AMPs. Plasmid pET30a/ His-EDDIE-GFP also provides green/white colony selection for high-throughput recombinant AMP cloning.
\end{abstract}

Keywords: antimicrobial peptide, high throughput, Npro, prokaryotic expression

\section{Background}

Antimicrobial peptides are widely distributed in nature and play a critical role in the innate immunity of host defense systems. They act with broad spectrum and, hence, are promising candidates for therapeutic and industrial application [1-5]. For research studies and

\footnotetext{
* Correspondence: ketao1@gmail.com; mabo1978@163.com

+ Contributed equally

'Department of Life Science and Technology, Nanyang Normal University, Wolong Road, Nanyang 473061, China

${ }^{3}$ Hubei Key Laboratory of Industrial Biotechnology, College of Life Science,

Hubei University, Wuhan 430062, China

Full list of author information is available at the end of the article
}

clinical trials, large quantities of these peptides are needed [6]. The number of described AMPs has increased over recent decades [7]; however, the recent generation of huge amounts of genomic, proteomic and EST (Expressed Sequence Tag) data enables novel strategies for the discovery of new candidate AMPs [8-10]. In silico methods based on bioinformatic analyses, combined with experimental screening techniques have been developed to screen and identify new AMP genes from huge "-omics" data sets [11,12]. Belarmino et al. screened 237,954 ESTs of sugarcane using a computational approach and successfully identified 17 new 
defensin isoforms [13]. Following in silico prediction, however, there is a requirement for a high throughput genome-scale DNA cloning and expression system to enable the antimicrobial activities of putative AMPs to be characterized $[9,14,15]$.

Expression of fusion proteins that form inclusion bodies has several advantages that can overcome major barriers of AMP expression in E. coli: high rates of expression, easy collection by centrifugation, protection from proteolysis and the avoidance of intrinsic AMP antimicrobial activity against host cells $[16,17]$. However, recombinant AMPs expressed in E. coli often include 1-2 non-native amino acid residuals at the $\mathrm{N}$ terminus of the target protein due to a specific linker sequence recognized by endoproteases or chemical agents, typically located between the native protein sequence and the tag [18]. These non-authentic $\mathrm{N}$ termini of AMPs often alter their characteristics. It is, therefore, very important to develop a new strategy for authentic recombinant AMP expression. The N-terminal autoprotease, Npro, of classical swine fever virus (CSFV) cleaves itself between the C-terminal Cys168 and position 169 [19], which represent the authentic N-terminal amino acid of the target protein. It is also a relatively hydrophobic protein that tends to form insoluble aggregates on refolding, preventing autoproteolysis [20]. In this approach, the target protein is fused to the $\mathrm{C}$-terminus of Npro and is expressed in inclusion bodies. After inclusion bodies are isolated, an in vitro refolding step is necessary to induce autoproteolysis, and render the AMPs biologically active [21]. Importantly, cleavage does not need to be initiated by the use of reducing agents or by temperature and $\mathrm{pH}$ shifts. EDDIE, a mutant of Npro, shows improved solubility and faster refolding and cleavage than wild-type Npro [16]. In our previous work, the fusion protein EDDIE-CAD was successfully expressed in $E$. coli after codon optimization and the purified recombinant mature Cecropin AD (CAD) was fully bioactive [22].

The in vitro cloning of DNA molecules traditionally uses PCR or site-specific restriction endonucleases to generate linear DNA inserts with defined termini and requires DNA ligase to covalently join these inserts to vectors with the corresponding ends [23]. However, restriction endonuclease sites often introduce a few amino acids to the $\mathrm{N}$-terminus of mature peptides, and it is very difficult to analyze recombinant clones when the insert DNA fragment is very short. For high throughput subcloning of short peptide genes, we constructed the vector, pET30a/His-EDDIE-GFP (Figure 1A), and used a

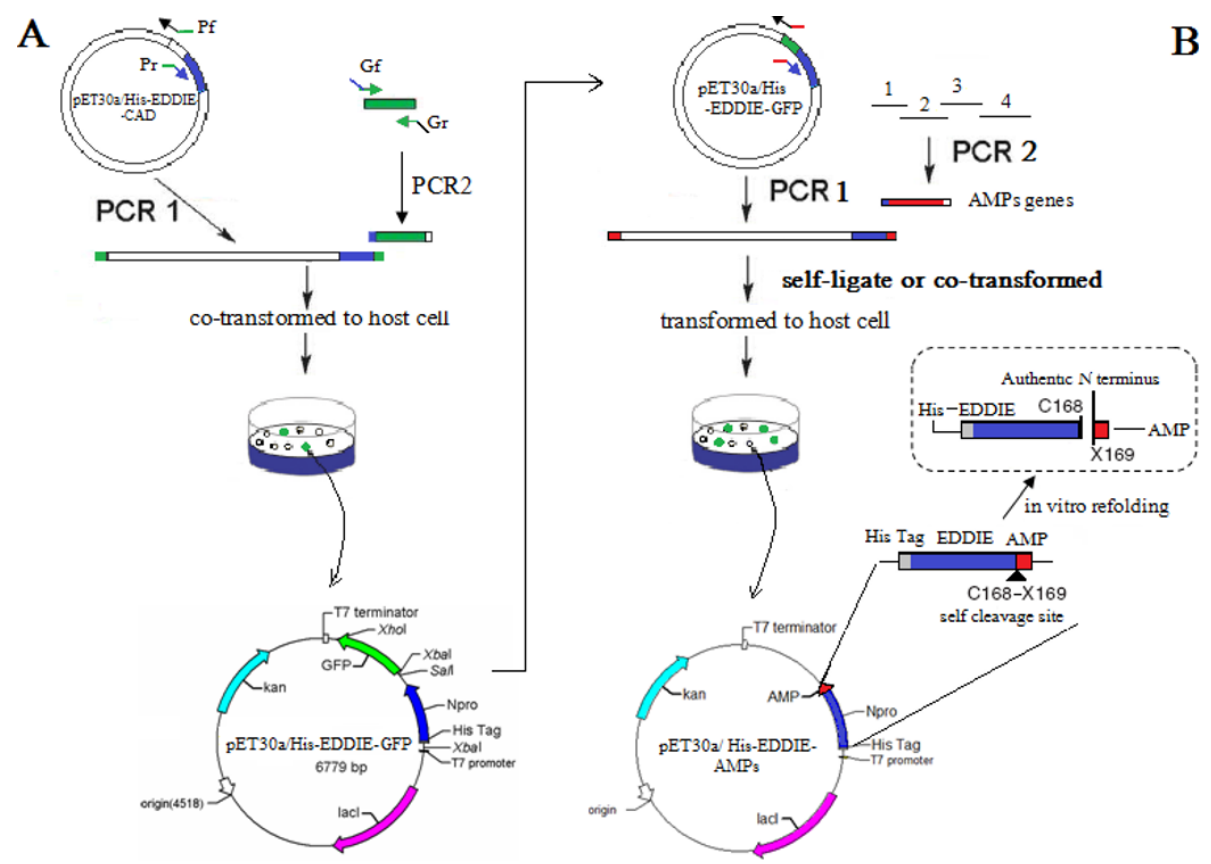

Figure 1 Schematic representation of the Construction of (A) pET30a/His-EDDIE-GFP and (B) pET30a/His-EDDIE-AMPs vectors. (A) pET30a/His-EDDIE-CAD was used to constructed pET30a/His-EDDIE-GFP. This plasmid was derived from pET30a and uses a T7-inducible promoter with lac operator, contains the low-copy pBR322 origin of replication, and encodes the kanamycin resistance gene (kanR) and the lac repressor gene (lacl). The GFP gene was inserted at the Sal I site and replaced CAD gene of pET30a/His-EDDIE-CAD, which at downstream positions of the EDDIE gene, give rise to the vector pET30a/His-EDDIE-GFP for expression of AMPs in E. coli. (B) The AMPs genes were inserted downstream of the carrier protein using overlap primer (arrows) at 168 site. The separate of AMPs and carrier partner between self-cleavage sites while in vitro refolding is shown in the square box, while the self-cleavage site is indicated by an arrow. 
seamless enzyme-free cloning method for high level expression of AMPs in E. coli, This method allows onestep assembly of DNA fragments in vivo via homologous recombination in E. coli [24]. For high level expression, codon usages of synthesized AMP genes were optimized according to the host strains. For efficient analysis of short insert DNA fragments, the recombinants were easily screened by GFP green/white colony selection. In this article, our approach was validated using 6 target AMPs of variable length.

\section{Results}

Construction of his-EDDIE-GFP fusion expression plasmid

The construction of the pET30a/His-EDDIE-GFP vector was based on pET30a/His- EDDIE-CAD. After PCR amplification, the GFP fragment was successfully subcloned into pET30a/His-EDDIE-CAD. Colonies showing green fluorescence were picked and PCR amplification of the GFP gene followed by gel electrophoresis showed that the GFP fragment had been successfully inserted into the expression vector (Figure 2A, B). DNA sequencing validated that the GFP gene was inserted downstream of the EDDIE gene.

\section{Construction of the his-EDDIE-AMP fusion expression plasmid}

To clone AMP genes in a high-throughput manner, we performed a green/white colony screen using the GFP in pET30a/His-EDDIE-GFP. After a target gene is
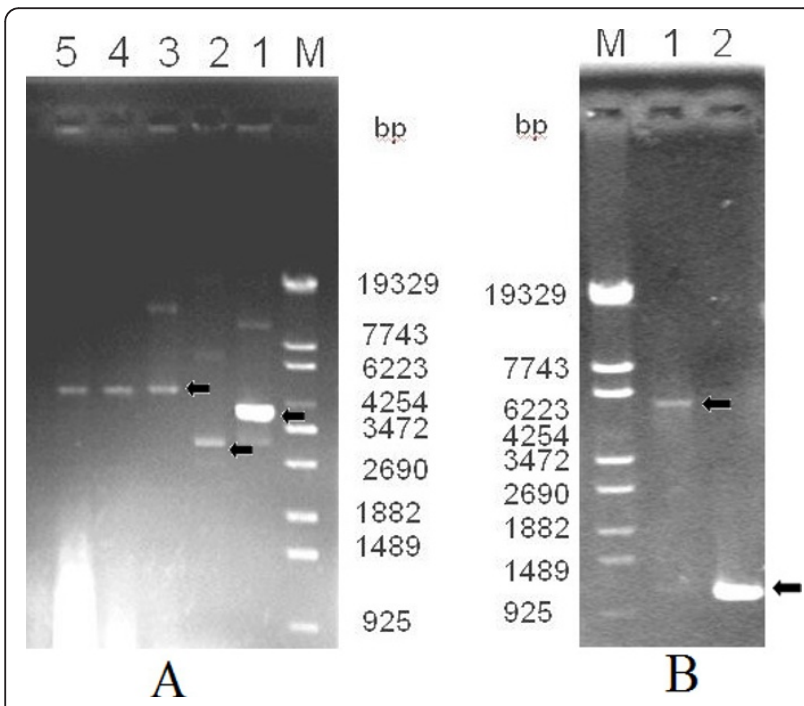

Figure 2 Agarose gel electrophoresis of the PCR products of the GFP gene and of plasmid pET30a/His-EDDIE-GFP. (A) Lane M: molecular weight marker; Lane 1: plasmid of pET30a/His-EDDIECAD; Lane 2: plasmid of pET30a; Lane 3-5: plasmid of pET30a/HisEDDIE-GFP; (B) Lane M: molecular weight marker; Lane 1: PCR products of linearized plasmid pET30a/His-EDDIE-GFP; Lane 2: PCR products of GFP genes used pET30a/His-EDDIE-GFP as template. cloned into the vector by a one-step PCR technique, the GFP gene is destroyed; therefore, green fluorescence indicates non-linearized parental vector. Four AMP genes, Temporin G, hexapeptide, Combi-1 and Histatin 9 were amplified and cloned downstream of EDDIE using a one-step $\mathrm{PCR}$ process, and then transformed into E. coli cells (Figure 3A). BLP-7 and Histatin 6 genes were assembled using four primers in one PCR reaction, respectively (Figure $3 \mathrm{~B}$ ). pET30a/His-EDDIEGFP was replicated at the same time. The two PCR products were then transformed into $E$. coli cells together. The transformants were screened under ultraviolet light, and the white colonies were further screened by PCR verification and sequencing. The recombinant pET30a/ His-EDDIE-AMP plasmid is smaller than the parental pET30a/His-EDDIE-GFP plasmid, which makes it very easy to distinguish the two plasmids by agarose gel electrophoresis (Figure 3C).

\section{Expression and purification of fusion proteins}

E. coli BL21 (DE3) cells harboring pET30a/His-EDDIEAMP were induced by IPTG, and the expression of HisEDDIE-AMP proteins was analyzed by SDS-PAGE (Figure 4). Fusion proteins of $20 \mathrm{kDa}$ represented the majority of the insoluble components in cell lysates. The recombinant His-EDDIE-AMPs were estimated to constitute about $40 \%$ of the total protein present in cells. The yield of inclusion bodies was quite high due to the properties of the fusion partner (high content of hydrophobic residues).

\section{Refolding and activity analysis}

Purified His-EDDIE-AMP inclusion bodies were diluted in optimized refolding buffer and incubated to enable self-cleavage to occur. To examine the antimicrobial activity of six recombinant AMPs, the purified supernatants were assayed using a radial diffusion assay. As

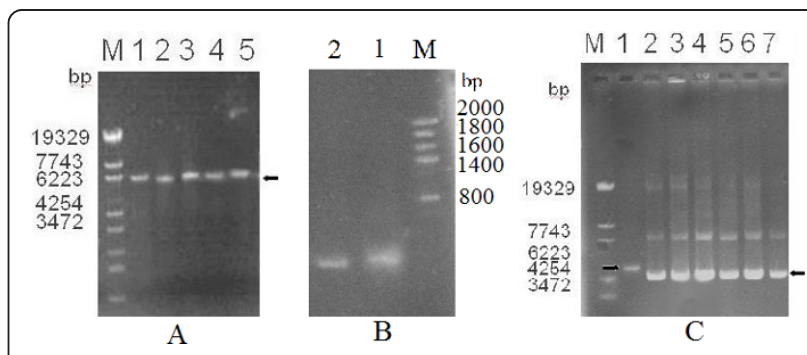

Figure $3 \mathrm{Gel}$ analysis of six recombinant pET30a/His-EDDIEAMP expression vectors. (A) Lane M: molecular weight markers: Lane 1-4: PCR product of four recombinant expression vector PETHis-EDDIE-AMPs; Lane 5: PCR product of vector pET-His-EDDIE-GFP; (B) Lane M: molecular mass makers; Lane 1-2: PCR product of Histatin6 and BLP-7 genes; (C) Lane M: molecular mass makers; Lane 1: plasmid of pET30a/His-EDDIE-GFP; Lane 2-7: plasmids of six pET30a/His-EDDIE-AMPs; 


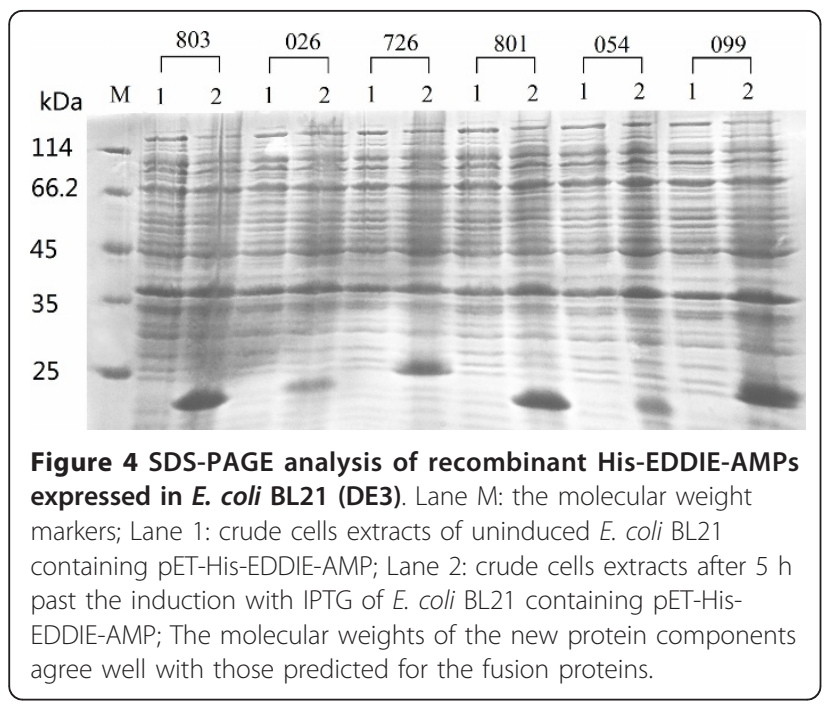

shown in Figure 5, there were large halos around the six AMPs, indicating that all six AMPs had specific bactericidal activities against E. coli ATCC2592, M. luteus or $S$. cerevisiae. No inhibition zones were seen around the negative control spots. The recombinant AMPs were clearly bioactive and very effective in killing these sensitive strains.

\section{Discussion}

We have described a new method for cloning and expressing AMP genes. The desired AMPs are amplified using ORF-specific primers with flanking sequences identical to the two ends of a linearized vector. The PCR product and the linearized vector are then cotransformed into E. coli cells, where the ORF is incorporated into the vector in vivo. Short AMPs can even directly incorporate into the linearized vector through self-ligation. Unlike conventional methods that use restriction enzymes or site-specific recombinases, PCR products could be seamlessly assembled without the need for specific sequences for ligation or site-specific recombination [25]. This system is more efficient than cloning methods requiring ligase $[26,27]$ and will be useful for standard DNA cloning and for constructing genome-scale clone resources that facilitate functional analysis [23].

Most AMP genes are very small (100-200 bases) and it is difficult to identify recombinant plasmids containing these genes. We, therefore, incorporated the GFP reporter gene into the expression vector to enable convenient recombinant colony picking.

AMPs expressed as Npro fusions are deposited as insoluble proteins in inclusion bodies. This greatly increases yield due to resistance to proteolytic degradation. During refolding in vitro, EDDIE self-cleaved at the specific site and the six target peptides were released. Our construct also encodes the (His) 6 affinity tag,
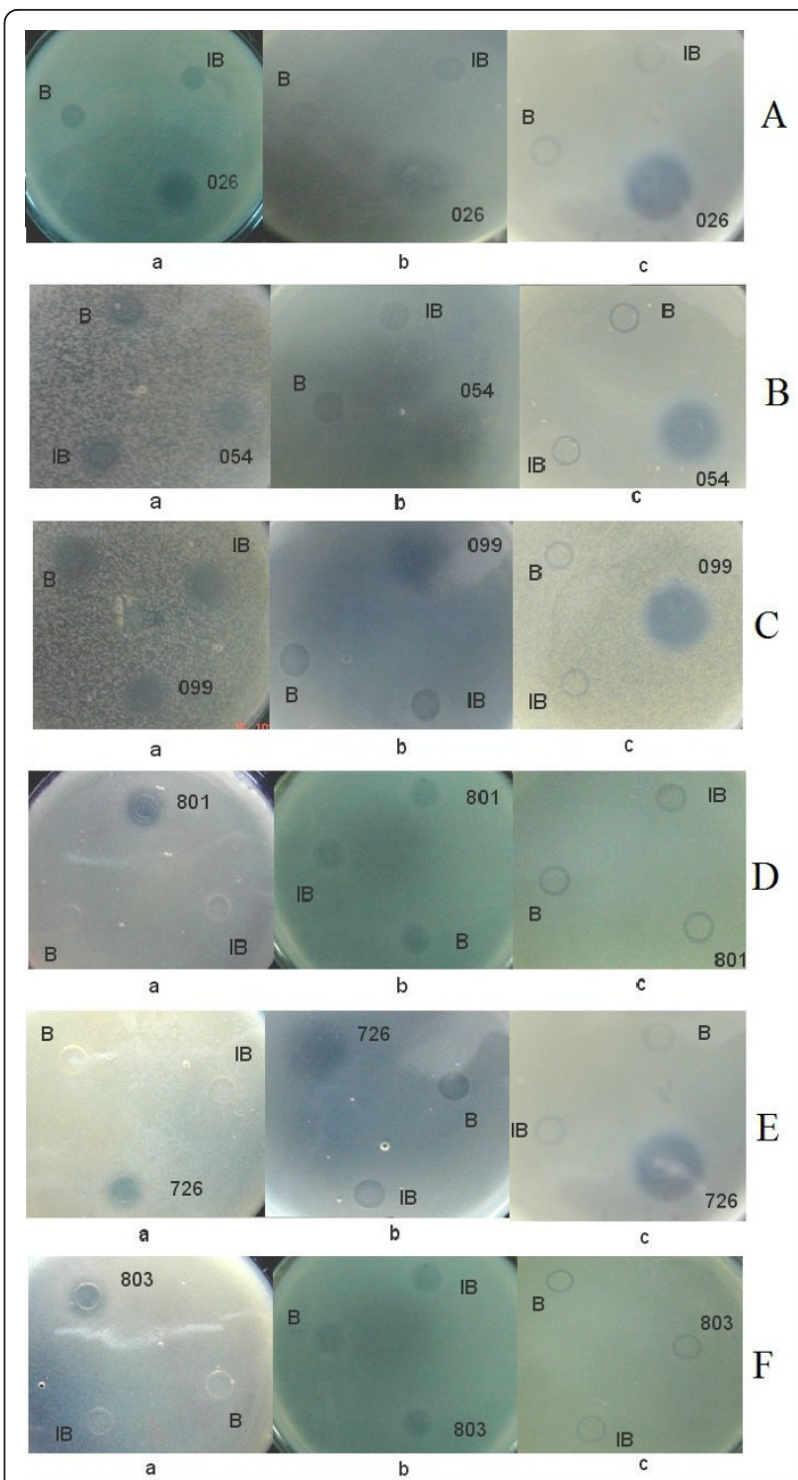

Figure 5 Detection of the antibacterial activities of candidate antimicrobial peptides against $E$. coli and $M$. luteus. B: refolding buffer; IB: Inclusion bodies of His-EDDIE-AMPs; a: antimicrobial activities assay against $S$. cerevisiae; b: antimicrobial activities assay against E. coli; C: antimicrobial activities assay against M. luteus; (A) 026, Hexapeptide; (B) 054, BLP-7; (C) 099, Temporin G; (D) 801, human Histatin 6; (E) 726, Combi-1; (F) 803, human Histatin 9.

Table 1 Primers for vector construction

\begin{tabular}{|c|c|}
\hline $\begin{array}{l}\text { Primer } \\
\text { name }\end{array}$ & Sequence $\left(5^{\prime}-3^{\prime}\right)$ \\
\hline $\mathrm{Pf}$ & GACACAGCGAACGGCGCAGCTGGTCACCCACAGCGGGCAAT \\
\hline $\operatorname{Pr}$ & GAGCTGTACAAGTGAAAGCTTGCGGCCGCACTCGAGCAC \\
\hline Gf & GCCGTTCGCTGTGTCGCACAAT \\
\hline $\mathrm{Gr}$ & TCACTTGTACAGCTCGTCCATGCCAT \\
\hline
\end{tabular}


Table 2 Antimicrobial peptides expressed in this research

\begin{tabular}{lllll}
\hline $\begin{array}{l}\text { AMP database } \\
\text { No. }\end{array}$ & Origin & Amino acid sequences of mature peptide & Length & Anti characteristics \\
\hline AP00054 & Bombinin-like peptide 7, BLP-7 & GIGGALLSAGKSALKGLAKGLAEHFAN & 27 & Gram + \& Gram- \\
\hline AP00099 & Temporin G & FFPVIGRILNGIL & 13 & Gram + \& Gram- \\
\hline AP00026 & Hexapeptide, LfcinB6 & RRWQWR & 6 & Gram + \& Gram-, Virus, Fungi, Cancer cells \\
\hline AP00726 & Combi-1 & RRWWRF & 6 & Gram + \& Gram-, Fungi \\
\hline AP00803 & human Histatin 9 & RKFHEKHHSHRGYR & 14 & Fungi \\
\hline AP00801 & human Histatin 6 & DSHAKRHHGYKRKFHEKHHSHRGYR & 25 & Fungi \\
\hline
\end{tabular}

preceding the coding regions of EDDIE, to enable fast and straightforward purification using $\mathrm{Ni}^{2+}$-chelating affinity chromatography after refolding. The target peptides could be easily purified to homogeneity.

These results validated this high throughput AMP subcloning method. Using this method, we successfully cloned 40 peptides into the expression vector and identified about 20 new AMPs from Brassica napus cDNA libraries that showed antimicrobial activities (data not shown). This approach, combined with bioinformatic analyses of genome and EST sequence data, will be useful in screening for new AMPs.

\section{Conclusions}

In conclusion, this is a simple, reliable, automated, robust, flexible and low-cost expression cloning approach in which PCR fragments are fused into an expression vector without unwanted amino acids. This strategy advances the methodologies available for AMP prokaryote expression. The main barriers to AMP expression, such as, codon preference, the intrinsic antimicrobial activity of AMPs to host cells, and inefficient production of AMPs owing to proteolytic degradation, are overcome by this expression system.

\section{Methods}

\section{Materials}

E. coli XL-GOLD (Stratagene, USA) was used as the host for subcloning and plasmid amplification. E. coli BL21 (DE3) was used as the host for expression of recombinant protein. E. coli ATCC2592 and M. luteus ACCC11001 were used as indicators in the antimicrobial assay of the six antimicrobial peptides. pET30a (Novagen, Madison, WI, USA) was used as a vector construction and

Table 3 Antimicrobial peptides expressed in this research

\begin{tabular}{|c|c|c|}
\hline AMPs & Name & Oligomer sequence $\left(5^{\prime}-3^{\prime}\right)$ \\
\hline \multirow[t]{2}{*}{ Hexapeptide } & $026 \mathrm{~F}$ & TTAACGCCATTGCCAGCGACGGCAGCTGGTCACCCACAG \\
\hline & $026 \mathrm{R}$ & CGTCGCTGGCAATGGCGTTAAAAGCTTGCGGCCGC \\
\hline \multirow[t]{2}{*}{ Combi-1 } & $726 \mathrm{~F}$ & TTAGAAACGCCACCAACGACGGCAGCTGGTCACCCACAG \\
\hline & $726 R$ & CGTCGTTGGTGGCGTITCTAAAAGCTTGCGGCCGC \\
\hline \multirow{2}{*}{$\begin{array}{l}\text { Temporin } \\
\text { G }\end{array}$} & $099 \mathrm{~F}$ & CAGAATGCGGCCAATGACCGGAAAAAAGCAGCTGGTCACCCACAG \\
\hline & 099R & ATTGGCCGCATTCTGAATGGCATCCTGTAAAAGCTTGCGGCCGC \\
\hline \multirow{2}{*}{$\begin{array}{l}\text { human } \\
\text { Histatin } 9\end{array}$} & $803 \mathrm{~F}$ & TGGCTGTGGTGTTCTCATGGAATTTACGGCAGCTGGTCACCCACAG \\
\hline & $803 R$ & AGAAACACCACAGCCATCGTGGGTATCGTTAAAAGCTTGCGGCCGC \\
\hline \multirow[t]{4}{*}{ BLP-7 } & $054-1$ & CTGTGGGTGACCAGCTGCGGCATTG \\
\hline & $054-2$ & GGGCGCTIITCCCGCGCTCAGCAGCGCGCCTCCAATGCCGCAGCTGGTC \\
\hline & $054-3$ & GCGGGAAAAAGCGCCCTGAAAGGCCTGGCGAAAGGCTTGGCGGAACATाT \\
\hline & $054-4$ & GCGGCCGCAAGCTITAATTCGCAAAATGTTCCGCCAAGCCTT \\
\hline \multirow{6}{*}{$\begin{array}{l}\text { human } \\
\text { Histatin } 6\end{array}$} & $801-1$ & CTGTGGGTGACCAGCTGC \\
\hline & $801-2$ & CTTATAGCCGTGATGACGCTTCGCATGGCTATCGCAGCTGGTCACCCACA \\
\hline & $801-3$ & AAGCGTCATCACGGCTATAAGCGCAAGTTTCACGAAAAACACCACAGCCA \\
\hline & $801-4$ & GCGGCCGCAAGCTITAACGATAACCACGATGGCTGTGGTGTIITCGT \\
\hline & backbone eF & TGAGATCCGGCTGCTAACAAAGCCC \\
\hline & backbone eR & GCAGCTGGTCACCCACAGCG \\
\hline
\end{tabular}


recombinant protein expression plasmid. Restriction enzymes NdeI and SalI were purchased from Takara (Dalian, China).

\section{Construction of the pET30a/His-EDDIE-GFP expression vector}

The plasmids containing the Npro mutant, EDDIE, were constructed according to Zhang et al. [22]. To enable green/white screening of recombinant clones (green colonies indicate the presence of uncut parental vector), the PCR primers Gf and Gr were designed according to the reported DNA sequence of GFP (GenBank accession no. ABN41558), with an added 18 bases flanking the sequences complementary to the two ends of linearized vector (Table 1 ). The $\mathrm{pET} 30 \mathrm{a} / \mathrm{His}$-EDDIE-CAD vector was amplified using primers Pf and $\operatorname{Pr}\left(25\right.$ cycles of $95^{\circ}$ $\mathrm{C}$ for $10 \mathrm{~s}, 65^{\circ} \mathrm{C}$ for $30 \mathrm{~s}$, and $72^{\circ} \mathrm{C}$ for 6 min using Pyrobest DNA polymerase; Takara Bio Inc., Shiga, Japan), and the linear PCR product, with 18 bases at each end homologous to GFP, was digested by $D p n I$ and purified. The plasmid was then generated by the seamless enzyme free cloning method [24], and was named pET30a/His-EDDIE-GFP (Figure 1). $5 \mu \mathrm{L}$ of purified PCR product (100-300 ng) and $1 \mu \mathrm{L}(50 \mathrm{ng})$ of the appropriately linearized vector were mixed and transformed into $50 \mu \mathrm{L}$ of $E$. coli XL-GOLD chemically competent cells by heat shock and then plated on selection plates (containing $50 \mu \mathrm{g} / \mathrm{mL}$ kanamycin). The recombinant colonies were easily selected by visualizing GFP fluorescence under ultraviolet light.

\section{Construction of the AMP expression vector with EDDIE as a fusion partner}

Six AMPs were selected from the AMP database [28] (Table 2). The AMP sequences were optimized according to $E$. coli codon usage. For short AMPs, the sense and antisense primers contained the reported DNA sequence and 18 bases of overlap with each other. Their 3 ' ends also contained the EDDIE C-terminal sequences and the ends of MCS of the vector, respectively. For longer AMPs, BLP-7 and Histatin 6, genes were assembled using 4 primers in a one-step PCR reaction. Vector was amplified with the PCR primers, backboneF and backboneR, which were designed according to the EDDIE C-terminal sequences and the ends of MCS of the vector, respectively (Table 3 ). The pET30a/HisEDDIE-GFP vector was amplified with the primers, and the linearized vector was purified and digested with DpnI. The PCR reaction was carried out for 25 cycles, each cycle consisting of $30 \mathrm{~s}$ at $94^{\circ} \mathrm{C}, 30 \mathrm{~s}$ at $62^{\circ} \mathrm{C}$, and 7 min at $72^{\circ} \mathrm{C}$. The PCR products covalently join to vectors with the corresponding ends in vivo when transformed into E. coli. White colonies were picked, and then sequenced to ensure that the coding sequence was correct. The resulting plasmids were named pET30a/ His-EDDIE-AMPs, respectively (Figure 1B).

\section{Expression and purification of fusion protein}

The pET30a/His-EDDIE-AMP plasmids were transformed into the expression host, $E$. coli BL21 (DE3) (Novagen, Madison, WI, USA). One colony was used to inoculate $50 \mathrm{~mL} \mathrm{LB}$ (1\% Bacto-tryptone, $0.5 \%$ yeast extract, and $8 \mathrm{mM} \mathrm{NaCl}$ ) medium supplemented with $50 \mu \mathrm{g} / \mathrm{mL}$ kanamycin, and grown overnight in a $37^{\circ} \mathrm{C}$ in a shaking incubator. The fully grown culture was mixed with $1 \mathrm{~L} \mathrm{LB}$ medium with the same antibiotics the next morning. The culture was grown at $25^{\circ} \mathrm{C}$, and IPTG was added to a final concentration of $1 \mathrm{mM}$ when the $\mathrm{OD}_{600}$ reached 0.5 . The culture was harvested $5 \mathrm{~h}$ later and the cells were washed and resuspended in $30 \mathrm{~mL}$ PBS buffer ( $\mathrm{NaCl} 137 \mathrm{mM}, \mathrm{KCl} 2.7$ mM, Na $\mathrm{HPO}_{4} 4.3$ $\mathrm{mM}, \mathrm{KH}_{2} \mathrm{PO}_{4} 1.4 \mathrm{mM}, \mathrm{pH}$ 7.2-7.4). The cells were lysed by freeze-thaw and the DNA was fragmented by ultrasonication. The insoluble inclusion bodies were isolated by $14,000 \times$ g centrifugation for $30 \mathrm{~min}$ in $4^{\circ} \mathrm{C}$. The pellet was washed three times with washing buffer $(10 \mathrm{mM}$ Tris/ $\mathrm{HCl}, \mathrm{pH} 7.6 ; 200 \mathrm{mM} \mathrm{NaCl}, 2$ mM 2-mercaptoethanol, and $1 \%$ Triton $\mathrm{X}-100)$ and then solubilized in denaturing buffer (8 $\mathrm{M}$ urea; $20 \mathrm{mM}$ Tris- $\mathrm{HCl}, \mathrm{pH}$ 7.6; and $5 \mathrm{mM}$ 2-mercaptoethanol).

\section{Refolding and activity analysis}

Purified His-EDDIE-AMPs inclusion bodies were refolded by rapid 1:50 dilution in optimized refolding buffer (500 mM NaCl, $20 \mathrm{mM}$ Tris, $2 \mathrm{mM}$ EDTA, 5\% glycerol, $10 \mathrm{mM}$ DTT, 0.01\% Tween-20, pH 7.5) and incubated at an appropriate temperature without stirring. During refolding, EDDIE restored its correct conformation and self-cleaved at the specific site, releasing AMPs from the fusion bodies. Renatured protein solution was then clarified by $15,000 \times \mathrm{g}$ centrifugation for $30 \mathrm{~min}$ in $4^{\circ} \mathrm{C}$. Then the insoluble sample was removed by filtering through $0.45 \mu \mathrm{m}$ membrane and AMPs were left in the supernatant. The supernatants were applied to a Ni-NTA His-bind column for purification.

Standard SDS-PAGE (12\% gel) was applied to assay fusion proteins. Band density was analyzed using a GELDOC 2000 gel documentation system (BIO-Rad, Hemel Hempstead, UK) and Quantity One software, version 4.4.0 was used to determine the fraction of target protein. EDDIE protein was quantified using a BCA protein assay kit (Pierce, Rockford, IL, USA). Antimicrobial activity of recombinant AMPs was detected using a radial diffusion assay [29]. Briefly, E. coli ATCC2592, $M$. luteus ACCC11001 and S. cerevisiae were grown to the mid-logarithmic phase and washed. Approximately $2 \times$ $10^{6} \mathrm{cfu} / \mathrm{mL}$ bacteria were incorporated into a thin $(1.2$ $\mathrm{mm}$ ) agarose underlay gel that contained $1 \%$ (wt/vol) 
agarose. Holes of $3.5 \mathrm{~mm}$ diameter were punched into the solidified agarose and these were filled with $100 \mu \mathrm{L}$ of AMP sample. After the plates were incubated for 12 $\mathrm{h}$ at $37^{\circ} \mathrm{C}$, the diameter of the clear zone surrounding each well was measured to evaluate the antimicrobial activity. Refolding buffer and inclusion bodies were used as negative controls. The above assays were performed in triplicate.

\section{Acknowledgements}

This work was supported by Genetically modified organisms major breeding projects (Grant No. 2009ZX08004-002B), the Research Planning Project of Basic and Advanced Technology of Henan Province, China (no.

112102310093), the Natural Science Foundation of Henan Educational Department, China (no. 2009B180018), the Open Project of Key Laboratory for Oil Crops Biology, the Ministry of Agriculture, PR China (201202) and the Funding of Nanyang Normal University (no. nynu200748).

\section{Author details \\ 'Department of Life Science and Technology, Nanyang Normal University, Wolong Road, Nanyang 473061, China. ${ }^{2}$ Key Laboratory of Biology and Genetic Improvement of Oil Crops, Ministry of Agriculture, Oil Crops Research Institute, Chinese Academy of Agricultural Sciences, No.2 Xudong Second Road, Wuhan 430062, China. ${ }^{3}$ Hubei Key Laboratory of Industrial Biotechnology, College of Life Science, Hubei University, Wuhan 430062, China. ${ }^{4}$ School of Environmental Science and Engineering, Huazhong University of Science and Technology, Wuhan 430074, China.}

\section{Authors' contributions}

TK and XDM made substantial contributions to conception and design. TK and SL carried out the experiments and wrote the manuscript. JBC and JXK participated in drafted the manuscript. JH, JYH and DQL participated in the experiments. HM, CHD and SYL participated in reviewing the manuscript and given final approval of the version to be published. All authors read and approved the final manuscript.

\section{Competing interests}

The authors declare that they have no competing interests.

Received: 31 August 2011 Accepted: 23 March 2012

Published: 23 March 2012

\section{References}

1. Koczulla AR, Bals R: Antimicrobial peptides: current status and therapeutic potential. Drugs 2003, 63(4):389-406.

2. Reddy KV, Yedery RD, Aranha C: Antimicrobial peptides: premises and promises. Int J Antimicrob Agents 2004, 24(6):536-547.

3. Dubin A, Mak P, Dubin G, Rzychon M, Stec-Niemczyk J, Wladyka B, Maziarka K, Chmiel D: New generation of peptide antibiotics. Acta Biochim Pol 2005, 52(3):633-638.

4. Boman HG: Antibacterial peptides: key components needed in immunity Cell 1991, 65(2):205-207.

5. Boman HG: Peptide antibiotics and their role in innate immunity. Annu Rev Immunol 1995, 13:61-92.

6. Li Y: Carrier proteins for fusion expression of antimicrobial peptides in Escherichia coli. Biotechnol Appl Biochem 2009, 54(1):1-9.

7. van't Hof W, Veerman EC, Helmerhorst EJ, Amerongen AV: Antimicrobial peptides: properties and applicability. Biol Chem 2001, 382(4):597-619.

8. Silverstein KA, Graham MA, Paape TD, VandenBosch KA: Genome organization of more than 300 defensin-like genes in Arabidopsis. Plant Physiol 2005, 138(2):600-610

9. Pestana-Calsa MC, Ribeiro IL, Calsa T Jr: Bioinformatics-coupled molecular approaches for unravelling potential antimicrobial peptides coding genes in Brazilian native and crop plant species. Curr Protein Pept Sci 2010, 11(3):199-209.

10. Xiao Y, Hughes AL, Ando J, Matsuda Y, Cheng JF, Skinner-Noble D, Zhang G: A genome-wide screen identifies a single beta-defensin gene cluster in the chicken: implications for the origin and evolution of mammalian defensins. BMC Genomics 2004, 5(1):56.

11. Gard AL, Lenz PH, Shaw JR, Christie AE: Identification of putative peptide paracrines/hormones in the water flea Daphnia pulex (Crustacea; Branchiopoda; Cladocera) using transcriptomics and immunohistochemistry. Gen Comp Endocrinol 2009, 160(3):271-287.

12. Christie AE: Neuropeptide discovery in Ixodoidea: an in silico investigation using publicly accessible expressed sequence tags. Gen Comp Endocrinol 2008, 157(2):174-185.

13. Belarmino LC, Capriles PV, Crovella S, Dardene LE, Benko-Iseppon AM: ESTdatabase search of plant defensins - an example using sugarcane, a large and complex genome. Curr Protein Pept Sci 2010, 11(3):248-254.

14. Silverstein KA, Moskal WA Jr, Wu HC, Underwood BA, Graham MA, Town CD, VandenBosch KA: Small cysteine-rich peptides resembling antimicrobial peptides have been under-predicted in plants. Plant $J$ 2007, 51(2):262-280

15. Oey M, Lohse M, Scharff LB, Kreikemeyer B, Bock R: Plastid production of protein antibiotics against pneumonia via a new strategy for high-level expression of antimicrobial proteins. Proc Natl Acad Sci USA 2009, 106(16):6579-6584

16. Achmuller $C$, Kaar W, Ahrer K, Wechner P, Hahn R, Werther F, Schmidinger H, Cserjan-Puschmann M, Clementschitsch F, Striedner G, Bayer K, Jungbauer A, Auer B: N(pro) fusion technology to produce proteins with authentic N termini in E. coli. Nat Methods 2007, 4(12):1037-1043.

17. Lee JH, Kim JH, Hwang SW, Lee WJ, Yoon HK, Lee HS, Hong SS: High-level expression of antimicrobial peptide mediated by a fusion partner reinforcing formation of inclusion bodies. Biochem Biophys Res Commun 2000, 277(3):575-580.

18. Arnau J, Lauritzen C, Petersen GE, Pedersen J: Current strategies for the use of affinity tags and tag removal for the purification of recombinant proteins. Protein Expr Purif 2006, 48(1):1-13.

19. Stark R, Meyers G, Rumenapf T, Thiel HJ: Processing of pestivirus polyprotein: cleavage site between autoprotease and nucleocapsid protein of classical swine fever virus. J Virol 1993, 67(12):7088-7095.

20. Cheng X, Lu W, Zhang S, Cao P: Expression and purification of antimicrobial peptide CM4 by Npro fusion technology in E. coli. Amino Acids 2010, 39(5):1545-1552.

21. Jungbauer A, Kaar W: Current status of technical protein refolding. $J$ Biotechnol 2007, 128(3):587-596.

22. Zhang Z, Ke T, Zhou Y, Ma X, Ma L: High expression of antimicrobial peptide Cecropin AD in Escherichia coli by fusion with EDDIE. Sheng Wu Gong Cheng Xue Bao 2009, 25(8):1247-1253.

23. Heyman JA, Cornthwaite J, Foncerrada L, Gilmore JR, Gontang E, Hartman KJ, Hernandez CL, Hood R, Hull HM, Lee WY, Marcil R, Marsh EJ, Mudd KM, Patino MJ, Purcell TJ, Rowland JJ, Sindici ML, Hoeffler JP: Genome-scale cloning and expression of individual open reading frames using topoisomerase I-mediated ligation. Genome Res 1999, 9(4):383-392.

24. Zhu D, Zhong X, Tan R, Chen L, Huang G, Li J, Sun X, Xu L, Chen J, Ou Y, Zhang T, Yuan D, Zhang Z, Shu W, Ma L: High-throughput cloning of human liver complete open reading frames using homologous recombination in Escherichia coli. Anal Biochem 2010, 397(2):162-167.

25. Muyrers JP, Zhang Y, Stewart AF: Techniques: Recombinogenic engineering-new options for cloning and manipulating DNA. Trends Biochem Sci 2001, 26(5):325-331.

26. lizasa $E$, Nagano $Y$ : Highly efficient yeast-based in vivo DNA cloning of multiple DNA fragments and the simultaneous construction of yeast/ Escherichia coli shuttle vectors. Biotechniques 2006, 40(1):79-83.

27. Olieric N, Kuchen M, Wagen S, Sauter M, Crone S, Edmondson S, Frey D, Ostermeier C, Steinmetz MO, Jaussi R: Automated seamless DNA cotransformation cloning with direct expression vectors applying positive or negative insert selection. BMC Biotechnol 2010, 10:56.

28. Wang Z, Wang G: APD: the Antimicrobial Peptide Database. Nucleic Acids Res 2004, 32(Database):D590-592.

29. Lehrer Rl, Rosenman M, Harwig SS, Jackson R, Eisenhauer P: Ultrasensitive assays for endogenous antimicrobial polypeptides. I Immunol Methods 1991, 137(2):167-173.

doi:10.1186/1472-6750-12-10

Cite this article as: Ke et al: A novel PCR-based method for high

throughput prokaryotic expression of antimicrobial peptide genes. BMC Biotechnology 2012 12:10. 